\title{
Introduction to Geographies of Darkness
}

Light pervades space and when it does not, darkness emerges and is usually vanquished with electric illumination. The perception of light and gloom is an existential dimension of experiencing space and time. Although rhythms of light and dark play out differently according to geography, all sighted people perceive, sense, act and construe meanings of space, place and landscape according to their diverse, changing qualities of luminosity and murkiness. Despite this shared, all-pervasive aspect of human experience, geographical investigation of daylight, darkness and illumination is meagre indeed. This dearth is startling when we consider how sunlight and shadow condition the appearance of landscape, the cultural values and meanings attributed to the luminous and shadowy qualities of place, and the alignment of diverse spatial practices with nightfall and dawn, for instance. It is as if place, space and landscape are by default, conceived as being washed in a neutral daylight, rather than being dynamically conditioned by vital light and dark.

This special issue focuses specifically on darkness, on how particular practices, cultural values and conceptions circulate around gloom, and have been continuously articulated and contested over time. The papers here explore different dark spaces, and endeavour to address John Jakle's complaint that 'landscape has been conceptualised primarily in terms of daytime use'i. They also elucidate how in contemporary times, darkness is being revalued in multiple ways.

These reappraisals are especially pertinent because darkness has been progressively banished through what Koslofskyi calls 'nocturnalisation', the expansion of social and economic activity into the night and the subsequent spread of illumination, a process persistently informed by religious and modernist discourses, and lasting fears about darkness. This 'colonization' 'iii proceeds as nightclubs extend opening hours, entertainment districts expand, all-night retail outlets multiply, and urban districts service the needs of shift workers.

Because we are habituated to ubiquitous illumination, it is difficult to imagine the pervasive darkness that formerly saturated most space after nightfall and the very real perils, discomforts and inconveniences that suffused everyday life. As Roger Ekirchiv details, numerous hazards proliferated after nightfall in medieval towns, with rubbish, ditches, excrement laden streets and overhanging timbers, not to mention the footpads, murderers and robbers who lurked in the dark. No wonder householders performed the daily ritual of 'shutting in', bolting doors and windows to guard against nocturnal intrusion or that many towns organized a night watch and locked the city gates to guard against malevolent interlopers. Inside houses, rudimentary candles provided 'small patches of light amid the blackness'v, requiring endless vigilance to keep them aflame. Yet despite these unpropitious conditions, pervasive darkness also solicited the development of practical competencies. These included navigation by star-filled skies and familiarity with the moon, its phases and the ways in which it transformed landscape, with the 'changing colours and 
contours in its shape-shifting light' providing a variety of possibilities according to James Attlee $^{\text {vi }}$, 'too subtle for our modern eye to appreciate'. Those who customarily navigated through dark space could locate themselves by sound and smell, and an enhanced tactile sense allowed distinctive surfaces and gradients to become recognizable, instilling a habitual, non-visual sensory familiarity with local landmarks and hazards.

In times of widespread superstition and religious fears, darkness was popularly conceived as a realm in which spectral, ungodly forces congregated. An assortment of malign spirits lurked, including imps, hobgoblins, ghouls, boggarts and witches, fuelled by shadowy appearances and phenomena such as marsh gas, or will o' the wisp. In contrast to these sinister forces, Christian belief is saturated with associations of light with divinity and goodness, ideas that were transmuted into emergent narratives that signified the transcendent shift from medieval ignorance to rationality and science. The enlightenment, as the term signifies, would 'shed light on all things' in the pursuit of 'truth, purity, revelation and knowledge'vii. Related allusions to darkness characterized particular spatial representations, notably the assignation of Africa as the 'Dark Continent' in British colonial discourse. Though persistent gloom has been ameliorated, negative associations continue to imbue contemporary understandings and values in common phrases such as the 'Dark Ages', 'dark forces', 'dark deeds', 'the dark net' and the 'dark side'. Yet while such negative resonances have predominated, practices and meanings that cherish gloom have invariably accompanied them.

In fact, there have been multivalent depictions of darkness across history. Koslofsky identifies how darkness has symbolized 'a diabolical night, nocturnal devotion, honest labour at night, and a night of drunken excess and indiscipline'viii, as well as promoting conviviality, intimacy, experimentation, excitement and spectacle. As Williams argues, urban darkness possesses no essential quality but is always socially mediated by practices and values: 'night spaces are neither uniform nor homogenous. Rather they are constituted by social struggles about what should and should not happen in certain places during the dark of the night'ix.

This signifies how darkness has been continuously subject to contestations over power. Otter writes about the strategies employed by the English Victorian bourgeoisie to order and regulate the nocturnal city with illumination, a biopolitical reordering of people through surveillance and an intensified vigilance towards the self. In public spaces, civil conduct could be exposed to view and esteemed 'qualities of reserve and distance maintained'x, augmenting the rational judgments required by liberal subjects. Significantly, the contrasting pervasive darkness of urban slums was conceived as a sign and cause of moral, intellectual and physical depravity, productive of social dislocation and inimical to social and economic dynamism.

Yet practices that positively value darkness have continuously contested these regulatory strategies to bathe the city in light. Widespread lantern smashing resisted the spread of 
illumination across early modern European cities $^{\times i}$ and as illumination has expanded, criminals, revolutionaries, subcultures, urban explorers, graffiti writers and others have operated under cover of darkness, challenging daytime norms of commerce, economic rationality and regulation ${ }^{\times i i}$. In the dark, persecuted minorities and lower classes have escaped domineering masters, carving out time in which to organise politically, and oppressed groups such as African-American slaves and Mesoamericans under brutal Spanish rule escaped the violence of imperial power by confining 'indigenous knowledge and practices to the hidden recesses of the night'xiii.

Williams focuses on how darkness threatens to 'deterritorialize the rationalizing order of society... when it obscures, obstructs, or otherwise hinders the deployment of the strategies, techniques, and technologies' of regulation ${ }^{\text {xiv }}$. However, the use of dark space as refuge has recently been countered by night vision equipment and motion-detecting and thermal imaging technologies that detect bodies. The advent of these hyperpanoptical techniques weakens the facility of darkness to provide cover from policing, although emergent modes of avoidance attempt to bypass them. The nocturnal city is thus subject to a shifting spatial politics whereby certain spaces are contingently commodified, regulated, claimed and abandoned by different parties.

In this issue, a lopsided ability to perceive and act in the dark is exemplified in Pip Thornton's compelling account of the deployment of overwhelming forms of light and darkness on the battlefield during the 2003 invasion of Iraq. The ability to operate in the dark with night vision equipment facilitated an ability to move behind enemy lines and leave evidence of presence, unnerving opposing forces. Techniques to illuminate soldiers' bodies so that they are visible to those with advanced night vision goggles further advance these perceptual asymmetries. More crucially, the mobilization of powerful light effects to dramatically interrupt darkness intimidated and destabilized civilians and military opponents was utilized in the allied strategy of 'shock and awe', affectively conveying apparently insuperable power..

The urban night has also served as a site of desire, as a 'second city - with its own geography and its own set of citizens' ${ }^{\prime x v}$ emerges when daylight fades. At night, witches, prostitutes, bohemians, beatniks, drug dealers, revolutionaries, conspirators and heretics emerge as clubs provide burlesque entertainment and music. Here, darkness is associated with libidinal desires, transgressive sexualities and mystical practices that contravene conventional wisdom. A phantasmagorical night-time city features in numerous cultural representations - in cinema, graphic fiction, advertisements, painting and photography - conjuring a nocturnal sublime, a 'realm of fascination and fear which inhabits the edges of our existence, crowded by shadows, plagued by uncertainty, and shrouded in intrigue'xvi, potentially replete with thrills and adventures. Darkness retains this potency, offering an occasion 'for trying to be someone the daytime may not let you be, a time for meeting people you should not, for doing things your parents told you not to do'xvii. 
Indeed, as illumination increasingly colonised areas of the $19^{\text {th }}$ century, contrasting areas of darkness, formerly conceived as inimical to pleasure, were associated with new desires and pleasures. For 19th century Parisian artists and writers, dark streets possessed a mystery at variance to the lit worldxviii, and new dark realms became sites of fascination, notably the tunnels, cellars and sewers which could be toured. Such fantasies resonate in later cinematic portrayals of subterranean gloom, in the atmospheric settings of the Viennese sewers in Carol Reed's The Third Man and the chiaroscuro aesthetics of film noir. Commercial sites of pleasure also marketed the attributes of darkness. At Vauxhall Gardens, the $18^{\text {th }}$ century pleasure grounds in London, an array of illuminated spectacles were supplemented by the dark attractions of the Hermit's Grotto, Submarine Caves and Dark Walk ${ }^{\mathrm{xix}}$. Fairgrounds offered rides in tunnels of love and ghost trains, soliciting spooky terrors that caused couples to cling to each other, initiating a transgressive, intimate physical contact. Darkness was also essential to the popular spiritualist séances held in the parlours of Victorian England, where mediums endeavoured to contact the deceased in an auspicious gloom - a condition that also enabled the performance of fraudulent manoeuvres ${ }^{\mathrm{x}}$. A more contemporary expression of the power of darkness to conjure up the supernatural is exemplified by the increasingly popular contemporary ghost hunts that take place after dark across western cities ${ }^{\times x i}$.

Besides these thrills, dark spaces have been associated with different positive attributes that supplant religious emphases on devilry and sin, and enlightenment assumptions about ignorance and primitiveness. Della Doraxxii explains the appeal of the gloomy caves for early ascetic Eastern Christians. Rather than offering the sensual plenitude and visual revelation offered by views from mountain peaks that conspicuously revealed God's work, caves were sites of prayer and retreat in which the absence of vision promoted religious intimations that it was beyond the capacity of humans to sense or represent the divine. Taoist dark meditation similarly enters dark space for short or prolonged periods. Desires for complete gloom were also integral to the practices of bardic schools of ancient Ireland, wherein young poets were sent to completely dark cells that were believed to offer the most fertile conditions in which to compose poetryxiii. Such sacred and meditative practices have been given renewed impetus by the rise of New Age practices ${ }^{x \times i v}$, including full sensory deprivation in flotation tanks and versions of the Native American traditional sweat lodge ceremony staged in very dark interiors.

More mundane, domestic practices have also taken place in darkness. Notably, before the advent of industrial work schedules and widespread illumination, sleep patterns were characterised by a first sleep - for around four hours after dark - followed by a second, shorter, lighter slumber. In between these two spells, an hour or two was spent in wakefulness, a welcome interlude from work that and provided opportunities to exchange stories, converse, have sex, engage in reverie, or pray ${ }^{\mathrm{x} v}$. This earlier use of darkness perhaps exemplifies how it might continue to serve as 'a conduit for new forms of conviviality and camaraderie'xxvi. In this issue, Rob Shaw investigates these potentialities, together with the aforementioned dimension of power, revealing the ambiguities that 
surround the home at night. Shaw discusses how an openness to otherness and enhanced intimacy and conviviality can be fostered in a homely darkness, yet this openness can also eventuate in an intensified sense of vulnerability, especially where darkness is utilized as an opportunity in which to exercise oppression and intimidation.

Outside the home, darkness is increasingly being sought with renewed vigor in multiple spaces, its manifold attributes increasingly recognized, revalued and celebrated ${ }^{x \times v i i}$. A key dimension is the potential for darkness to reconfigure and challenge the ways even familiar spaces are sensed. At an expansive spatial scale, darkness reconfigures the visual sensing of landscape. Just as we see with the landscape ${ }^{x \times v i i i}$ and with the daylight that shines upon it, so too we see with the darkness, though we might not see much at all. In gloomy settings, we begin to discern more as the eye's rod cells adjust to the limited, changing levels of light that emerge, to which we constantly attune $e^{\text {xxix }}$. Greys and blacks predominate and the gaze is attracted to evident shiny forms and patches that stand out against the blackness, and the night sky, often more vividly luminous than the land. We also see in total darkness, as Sorensen insists, though 'not what we generally wish to see or in the manner we generally wish to see ${ }^{\prime \times x x}$.

Besides this transformation of visual experience, darkness also foregrounds usually subservient non-visual sensations ${ }^{x \times x i}$. Tallmadge asserts that in daylight, the dominance of visual apprehension means that the 'ubiquity and pervasiveness of light make everything stand out in hard-edged clarity', yet vision 'allows us to know things only by their surfaces'xxxii. In darkness, he contends, we become attuned to the landscape through other senses, and the body 'relaxes, opens, breathes, extends its attention outward into the world the way a plant feels its way into the soil with roots or into the air with leaves' $x \times x$ iii. Moreover, diverse modes of moving - running ${ }^{\times \times \times i v}$, cycling ${ }^{\times \times \times v}$, driving ${ }^{\times \times x v i}$ and traintravellingxxxvii - offer distinctive sensory engagements with dark landscape, reconfiguring visual apprehension and foregrounding tactility, smell and sound.

In particular interior spaces too, darkness offers intensified and alterative sensory and social experiences. The 'darkrooms' within gay subculture offer a space in which men may seek out anonymous sexual intimacy with others. Darkness is also deployed at art events $^{\times \times x v i i i}$ that theatricalize landscapes or explore perceptual and social adaptation, and concerts $^{x \times x i x}$ and plays ${ }^{x l}$ use gloom to focus attention on sound. In this issue, Edensor and Falconer examine how dining in the dark at a London restaurant foregrounds a range of non-visual perceptions that can be intriguing, frightening or thrilling according to disposition and perspective. In this setting, darkness has the potential to defamiliarize the apprehension of space whilst also soliciting social interactions and intimacies that are less constrained by judgments based on appearance, and imaginative conjecture about the unseen space. Importantly, these modes of sensing space otherwise induce reflexivity about habitual, ordinary experience, revealing how culturally circumscribed and habitual are the usual sensations that we take for granted. 
The notion that gloom is inimical to rich sensory experience is famously countered by Junichiro Tanizaki's ${ }^{x i i}$ celebration of the subtleties of gloom in contrast to the spread of illumination across Japan. Tanizaki provides an exquisite depiction of the appearance of Japanese lacquerware in a darkened room, the effects of candlelight, and the dark depths of alcoves and recesses, that contrast with the garish over-ornamentation of western interior décor. The historical moment is crucial here, and reveals how the social and spatial contexts in which darkness is encountered are crucial to assessing responses of those immersed within it. Nye ${ }^{\text {xli }}$ illustrates this in his account of how responses to successive blackouts in New York City have been influenced by the fears, desires, constraints and opportunities that circulated during their occurrence. For instance, the 1965 New York citywide blackout engendered convivial conversation as social barriers dissolved and inhibitions weakened under the shared conditions of darkness, producing a liminal, somewhat festive state. This celebratory mood wholly contrasted with the blackout of 1977. As the city slumped under conditions of inflation, unemployment, over-zealous policing and widespread social mistrust, the blackout became emblematic of this social and economic discord. As rioters, looters and arsonists sought to capitalise on the conditions afforded by darkness, the blackout seemed to signal social breakdown and forewarned of a potentially dystopian future.

In recent years, the perceived over-illumination of space is the key social context that has triggered a renewed search for darkness. The gradual disappearance of darkness from most space is increasingly lamented, as massive expenditure of energy keeps cities illuminated throughout the night and bird and insect migration rhythms are disturbed. James Attlee considers that globally, only 'the great deserts and oceans offer large areas of darkness'xliii, with most of us 'condemned to simmer in our own electric bouillabaisse' ${ }^{\text {xliv }}$. According to Nye, the ability to perceive nocturnal space is curtailed since most people 'know only an artificial darkness that is fogged with electric light', with the sky 'a smudged and meaningless background' ${ }^{\prime}{ }^{1}$.

Gallawayxvi summarizes the values associated with dark skies as a 'source of aesthetic, scientific and spiritual inspiration ....a natural resource, a scenic asset and part of humanity's cultural heritage'. Meierxvii shows how a coalition of interests has aligned in campaigns to designate dark sky parks in Canada, the USA and Germany, where astronomers, environmentalists and heritage preservationists articulate divergent values but converge in agreement about the desirability of designation. In this issue, and more specifically, Oliver Dunnett explores the response to over-illumination in the British Dark Sky movement, examining how their advocacy amplifies the longstanding opposition between an 'artificial' and malign city, and a 'natural' and 'traditional' rural.

Other contemporary approaches to seeking more sustainable engagements with energy, light and darkness include those who move away from illuminated space. In this issue, Phillip Vannini and Jonathan Taggart focus on how Canadian off-gridders adapt to the shifting availability of daylight according to season and weather through the use of solar 
power devices, using the limited obtainable energy gathered to provide light when it is most necessary. Darkness is conceived as a positive condition, lived with and accommodated, perhaps signaling a future in which electric illumination is variable and partial. This seems to accord with Gallan's ${ }^{\text {xviii }}$ argument that we should engage in 'becoming crepuscular' in more creatively orientating everyday lives around light and dark.

The papers in this special issue underline how darkness cannot be considered as an essentially neutral, positive or negative quality at all for the assessment and experience of gloom is contingent on prevailing cultural values, fears and desires. Variations of gloom are multiple, ranging from twilight to pitch black. As Morris insists, light and dark are both present in each other, and condition the reception of each other, and since 'perception shuttles between extremes of light and dark', she argues, darkness is 'situated, partial and relational' ${ }^{\prime}$.ix. In this context, these papers emphasize that the relationship of light and dark is being progressively reconfigured in ways that do not diminish darkness as a subordinate, inferior condition 
i Jakle, J. (2001) City Lights: Illuminating the American Night, Baltimore: Johns Hopkins University Press, (p. vii)

ii Koslofsky, C. (2011) Evening's Empire: A History of Night in Early Modern Europe. Cambridge: Cambridge University Press

iii Melbin, M. (1978) ‘Night as frontier’ American Sociological Review, 43(1): 3-22

iv Ekirch, R. (2005) At Day's Close: Night in Times Past. London: W.W.Norton and Company

v Ekirch, 'At day's...', p. 100

vi Attlee, J. (2011) Nocturne: A Journey in Search of Moonlight, London: Hamish Hamilton (p. 5)

vii Bille, M. and Sørensen, T. (2007) 'An anthropology of luminosity: the agency of light', Journal of Material Culture, 12(3): 263-284 (p. 272)

viii Koslofsky Evening's Empire... p. 5 
ix Williams, R. (2008) 'Nightspaces: darkness, deterritorialisation and social control', Space and Culture, 11(4): 514-532 (p. 514)

x C. Otter, The Victorian Eye: A Political History of Light and Vision in Britain, 18001910, (Chicago: University of Chicago Press, 2008), p. 3

xi Schivelbusch, W. (1988) Disenchanted Night: The Industrialisation of Light in the Nineteenth Century, Oxford: Berg.

xii B. Palmer, Cultures of Darkness: Night Travels in the Histories of Transgression: From Medieval to Modern, (New York: Monthly Review Press, 2000).

xiii Galinier, J., Becquelin, A., Bordin, G., Fontaine, L., Fourmaux, F., Ponce, J., Salzarulo, P., Simonnot, P., Therrien, M. and Zilli, I. (2010) 'Anthropology of the night: crossdisciplinary investigations', Current Anthropology, 51(6): 819-847 (p. 828)

xiv Williams 'Nightspaces...' p. 518

xv W. Sharpe, New York Nocturne: The City after Dark in Literature, Painting and Photography, 1850-1950, (Princeton: Princeton University Press, 2008), p. 14

xvi Sharpe, New York... p. 9 
xvii van Liempt, I., van Aalst, I. and Schwanen, T. (2015) Introduction: Geographies of the urban night, Urban Studies, 52(3): 407-421 (p. 408)

xviii Bressani, M. (2015) 'Light into darkness: gaslight in Nineteenth century Paris', in S. Isenstadt, M. Petty and D. Neumann (eds) Cities of Light: Two Centuries of Urban Illumination, London: Routledge

xix Barnaby, A. (2009) 'Light Touches: Cultural Practices of Illumination, London 17801840', unpublished PhD thesis, University of Exeter

xx Holloway - seance

$x x i$

Holloway, J. (2010) Legend-tripping in spooky spaces: ghost tourism and infrastructures of enchantment', Environment and Planning D: Society and Space, 28: 618-637

xxii V. Della Dora, 'Anti-landscapes: caves and apophasis in the Christian east', Environment and Planning D: Society and Space, 29, 2011, pp. 761- 779

xxiii C. Raymo, C. (2008) 'Why the night sky is dark', in P. Bogard (ed), Let There Be Night: Testimony on Behalf of the Dark, (Reno: University of Nevada Press, 2008). 
xxiv Heelas, P. (1996) The New Age Movement: The Celebration of the Self and the Sacralization of Modernity, Oxford Blackwell

xxv Ekirch At Night's Close

xxvi B. Gallan and C. Gibson, 'Commentary: new dawn or new dusk? Beyond the binary of night and day', Environment and Planning A, 2011, pp.2516-2532 (p. 2514)

xxvii Bogard, P. (ed) (2008) Let There Be Night: Testimony on Behalf of the Dark. Reno: University of Nevada Press

xxviii Wylie, J. (2006) 'Depths and folds: on landscape and the gazing subject', in Environment and Planning D: Society and Space, 24: 537-554

xxix Lingis, A. (1998) Foreign Bodies, Bloomington, In: Indiana University Press

xxx Sorensen, R. (2004) 'We see in the dark', Nous, 38(3): 456-480 (p. 457 )

xxxi T. Edensor, 'Reconnecting with Darkness: experiencing landscapes and sites of gloom', Social and Cultural Geography 14(4), 2013, pp. 446-465 
xxxii Tallmadge, J. (2008) Night vision, in P. Bogard (ed) Let There Be Night: Testimony on Behalf of the Dark. Reno: University of Nevada Press (p. 142)

xxxiii Tallmadge 'Night vision' $p .140$

xxxiv Edensor, T. and Lorimer, H. (2015) Landscapism' at the Speed of Light: darkness and illumination in motion', Geografiska Annaler: Series B, Human Geography , 97(1): $1-16$

xxxV Cook, M and Edensor, T. (2014): 'Cycling through dark space: apprehending landscape otherwise', Mobilities, DOI: 10.1080/17450101.2014.956417

xxxvi Isenstadt, S. (2011) 'Auto-specularity: driving through the American night', Modernism/Modernity, 18(2): 213-231

xxxvii Bissell, D. (2009) 'Visualising everyday geographies: practices of vision through travel-time', Transactions of the Institute of British Geographers, 34(1): 42-60

xxxviii Edensor and Lorimer, 'Landscapism'...; 2015; Morris, N. (2011) 'Night walking: darkness and sensory perception in a night-time landscape installation', Cultural Geographies, 18(3): $315-342$ 
xxxix Edensor, T. (2015b) 'Light design and atmosphere', Journal of Visual Communication, 14(3): 331-350

xI Welton, M. (2013) 'The possibility of darkness: blackout and shadow in Chris Goode's Who You Are', Theatre Research International, 38(1): 4 - 19

xli Tanizaki, J. (2001) In Praise of Shadows, London: Vintage Classics.

xlii Nye, D. (2010) When the Lights Went Out: A History of Blackouts in America. MIT Press: Cambridge, Massachussets

xliii Attlee, 'Nocturne...', p. 3

xliv Attlee, 'Nocturne...' p 9

xIv Nye,, 'When the lights...', p. 9

xlvi Gallaway, T. (2015) 'The value of the night sky', in J. Meier, U. Hasenöhrl, K. Krause and M. Pottharst (eds) Urban Lighting, Light Pollution and Society, London: Routledge (p. 280) 
xlvii Meier, J. (2015) 'Designating dark sky areas: actors and interests', in J. Meier, U. Hasenöhrl, K. Krause and M. Pottharst (eds) Urban Lighting, Light Pollution and Society, London: Routledge

xlviii Gallan, B. (2014) 'Becoming crepuscular: rethinking the human relationship to day and night', unpublished PhD thesis, University of Wollongong, NSW, Australia

xlix Morris, 'Nightwal;king...', p. 316 